\title{
Curability, Workability and Stability Investigation on a Novel Pure Liquid One Component Thermal Curable Epoxy Adhesive
}

\author{
Chunfu Chen ${ }^{1,}$, Bin $\mathrm{Li}^{2}$, Masao Kanari ${ }^{1}$, Daoqiang $\mathrm{Lu}^{2}$ \\ ${ }^{1}$ Henkel Technology Center-Asia Pacific, Henkel Japan Ltd, Yokohama, Japan \\ ${ }^{2}$ Henkel Adhesive Innovation Center, Henkel (China) Co, Ltd, Shanghai, China
}

Email address:

chunfu.chen@henkel.com (Chunfu Chen)

${ }^{*}$ Corresponding author

To cite this article:

Chunfu Chen, Bin Li, Masao Kanari, Daoqiang Lu. Curability, Workability and Stability Investigation on a Novel Pure Liquid One Component Thermal Curable Epoxy Adhesive. Advances in Materials. Vol. 8, No. 2, 2019, pp. 94-99. doi: 10.11648/j.am.20190802.16

Received: April 3, 2019; Accepted: May 23, 2019; Published: June 29, 2019

\begin{abstract}
A novel one component thermal curable epoxy adhesive composed of all liquid reactive ingredients was developed recently. Its thermal cure behavior was measured and analyzed with differential scanning calorimetry isothermal method. Workability and pot life at room temperature as well as storage stability and shelf life under chilled, frozen conditions were measured and analyzed by monitoring its viscosity change during the storage period. The measurement results confirmed that the novel one component epoxy adhesive can cure well at relatively low temperature and its pot life is much longer than conventional two component epoxy adhesives with similar curability and adhesion performance. The novel one component epoxy adhesive was also confirmed to be very stable and its shelf life can be several years long under suitable frozen storage. Based on cure behavior measurement results, cure kinetics of the novel one component epoxy adhesive was investigated. Arrhenius equation obtained from kinetics plot curve was applied to predict pot life and shelf life and it was found that the predicted pot life and shelf life correlate very well with actual measured results. Crystallization temperature of the novel epoxy adhesive was also measured and found to have close relationship with storage stability. This study verified that differential scanning calorimetry isothermal method can be used to predict shelf life of one component epoxy products. In addition, crystallization temperature measurement can be utilized for better stable epoxy adhesive development and suitable storage temperature determination.
\end{abstract}

Keywords: Epoxy, Adhesive, One Component, Thermal Cure, DSC, Pot Life, Shelf Life, Curability, Stability, Crystallization Temperature

\section{Introduction}

Epoxy adhesives have been widely used in various applications ranging from general purpose, semiconductor packaging, electronics assembly, automobile production to aerospace industry because of their cured strong chemical structural network and high adhesion to different kinds of substrates [1-5]. Epoxy adhesives are usually supplied in two components by mixing and packing epoxy resin composition separated from curing agent composition due to high reactivity between epoxy resin and curing agent once mixed together. In recent decades, one component epoxy adhesives which contain all formulated compositions including epoxy resins and curing agents have become more and more important especially for high production efficiency required applications such as semiconductor packaging, electronics assembly and automobile productions [6-9]. One component epoxy adhesive normally needs elevated temperature cure. Various latent curing agents have been developed and commercialized. Most of commercially available latent curing agents, such as dicyandiamide, modified imidazole or polyamine type fine powders, are in solid state [10-13]. Solid type latent curing agent, usually dispersed in epoxy resin as one component material in appearance, has much lower reactivity with epoxy resin at room temperature because of much smaller contact opportunity with epoxy group as compared to liquid type curing 
agent. It will melt and dissolve in epoxy resin and start to cure epoxy resin at certain elevated temperature. The solid latent curing agents, however, often cause incomplete cure problems resulting from insufficient dissolving in actual uses [14].

Research and development on liquid type latent curing agents have been attracted attentions in the past years to resolve incomplete cure problems [15-17]. Recently we have developed a novel pure liquid one component thermal curable epoxy adhesive that is composed of all liquid reactive components including blend epoxy resins, a liquid type latent curing agent and an accelerator [18]. The novel pure liquid one component epoxy adhesive has achieved qualification in one high end electronics assembly application where normal one component epoxy adhesive is not suitable for use due to serious un-cure problem at very narrow areas.

One component thermal cure type epoxy adhesive should have fast curability at certain elevated temperature, acceptable level workability for uses at room temperature and good stability during storage. Pot life, defined as the storage time when viscosity increases to twice of initial one, is one key factor for adhesive workability determination. Shelf life is the maximum storage time at the designed storage condition, usually in refrigerator or freezer for one component thermal curable epoxy adhesive, during which the adhesive can be still used with no obvious property changes. Determination of shelf life, however, is based by far on real time measurement at the designed storage temperatures. The determination normally needs up to several months or even years and always causes delay of introduction of new one component thermal cure epoxy adhesive product to the market. Differential scanning calorimetry, abbreviated commonly as DSC, is the most popular method used to determine curability of thermoset resins including one component thermal cure epoxy adhesives. DSC has also been used for the kinetics reaction study on epoxy adhesives [19-26].

In this study, the newly developed novel pure liquid one component thermal cure epoxy adhesive is selected as adhesive material. Pot life and shelf life are measured by monitoring the viscosity change at the set temperatures. Curability is measured at various cure temperatures by DSC isothermal method. Kinetics curve is plotted based on DSC isothermal measurement result. Regression of the curability and workability, stability is studied and discussed. Stability behavior at frozen storage has also been investigated and discussed.

\section{Method}

\subsection{Adhesive Material}

The newly developed pure liquid one component thermal curable epoxy adhesive was used directly for measurement and analysis without any modification. This novel epoxy adhesive is composed of blend epoxy resins with a liquid type latent modified imidazole curing agent and a liquid accelerator. All these components are reactive components in liquid state. It appears as an amber liquid at room temperature. Initial viscosity is $7100 \mathrm{mPas} / 25^{\circ} \mathrm{C}$. Glass transition temperature is $121^{\circ} \mathrm{C}$, measured with TMA (Thermal Mechanical Analysis) method by cured @ $90^{\circ} \mathrm{C}$ for 60 minutes.

\subsection{Viscosity Measurement}

Viscosity was measured at $25^{\circ} \mathrm{C}$ by HAAKE RheoStress 3000 Viscometer with the use of a $2^{\circ} \mathrm{C}$ one. Adhesive samples stored in a refrigerator or freezer were thawed to room temperature for 30 minutes before testing. Adhesive sample cured at $90^{\circ} \mathrm{C}$ was cooled momently down to room temperature by using a cool dryer.

\subsection{DSC Measurement}

Cure behavior of the novel epoxy adhesive was measured by PerkinElmer Pyris 1 Differential Scanning Calorimeter at temperatures of $80^{\circ} \mathrm{C}, 90^{\circ} \mathrm{C}, 100^{\circ} \mathrm{C}, 110^{\circ} \mathrm{C}, 120^{\circ} \mathrm{C}, 130^{\circ} \mathrm{C}$, $140^{\circ} \mathrm{C}$ and $150^{\circ} \mathrm{C}$. Standard isothermal method was used to analyze the result. Crystallization temperature of the novel epoxy adhesive was measured by DSC with a scanning rate of $5^{\circ} \mathrm{C}$ per minutes starting from $-60^{\circ} \mathrm{C}$ to $250^{\circ} \mathrm{C}$.

\section{Result}

\subsection{DSC Cure Behavior}

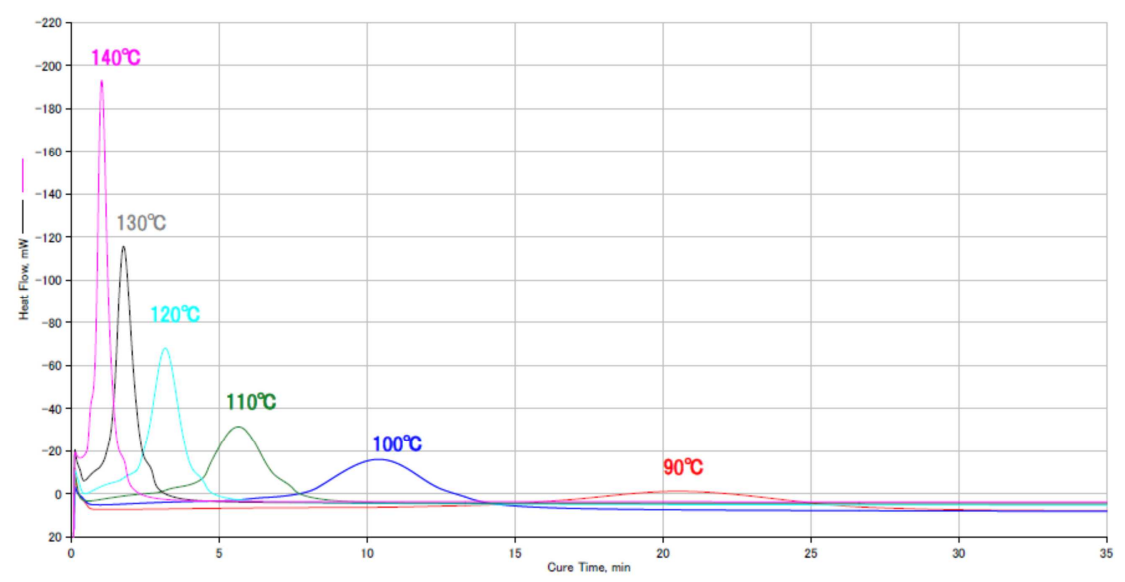

Figure 1. DSC Isothermal Cure Chart. 


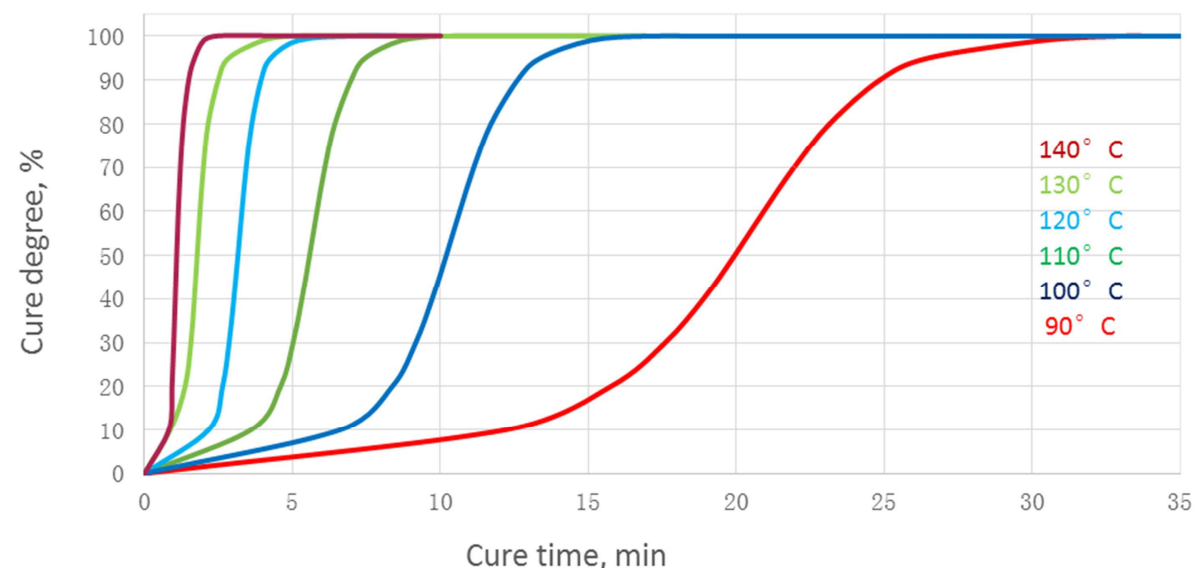

Figure 2. Cure Degree vs Cure Time.

Curability of the novel epoxy adhesive was measured at various temperatures ranging from $80^{\circ} \mathrm{C}$ to $150^{\circ} \mathrm{C}$ by isothermal DSC method. DSC isothermal results measured at $90^{\circ} \mathrm{C}$ to $140^{\circ} \mathrm{C}$, were shown in Figure 1 . It can be seen that full cure of the novel epoxy adhesive can be almost achieved within 30 minutes at $90^{\circ} \mathrm{C}$, within 10 minutes at $110^{\circ} \mathrm{C}$ and within 5 minutes at $130^{\circ} \mathrm{C}$, respectively. Figure 2 shows cure degree vs. cure time at various testing temperatures. DSC testing results clearly confirmed that the novel epoxy adhesive possesses very good curability. It can cure well within 30 minutes at relatively low temperature of $90^{\circ} \mathrm{C}$. Cure time can be further shortened to within 5 minutes at temperatures with higher than $130^{\circ} \mathrm{C}$.

\subsection{Viscosity Stability and Pot Life}

Viscosity change is commonly used to check work time of epoxy adhesive products. Figure 3 shows viscosity measurement results of the novel epoxy adhesive stored at $25^{\circ} \mathrm{C}$. At the beginning stage, viscosity increasing rate was relatively moderate. It became much faster after stored around 20 hours. Its pot life, the storage time at which the viscosity increases to two times of initial one, is measured at 19.2 hours from Figure 3. This pot life is much longer than only less than two hours of conventional two component epoxy adhesives that have similar curability and product performance.

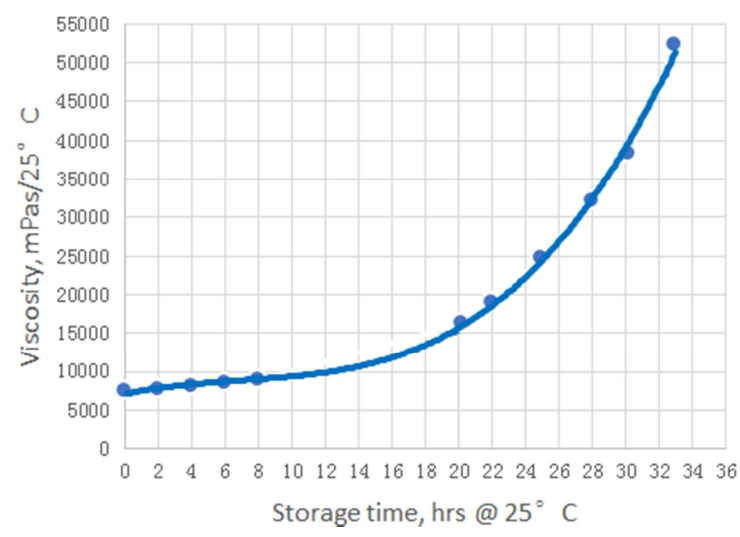

Figure 3. Viscosity Stability at Room Temperature.

\subsection{Storage Stability and Shelf Life}

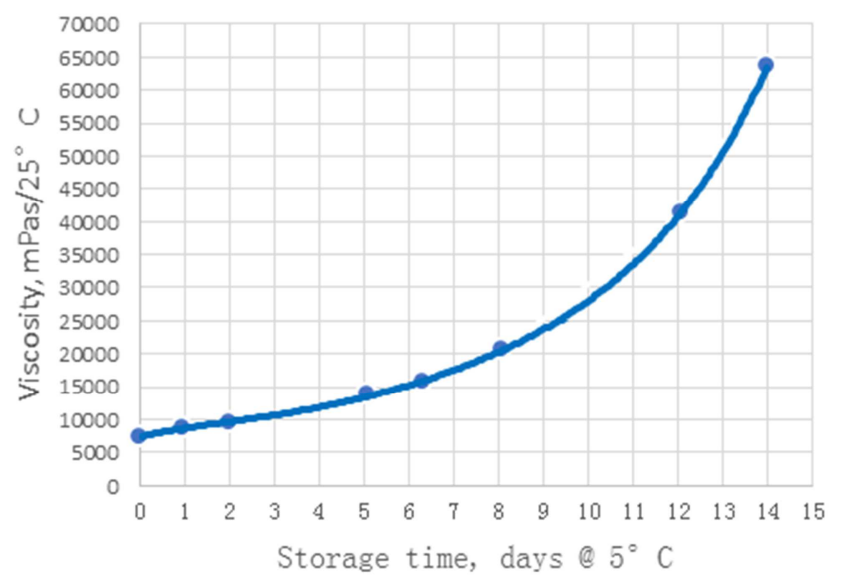

Figure 4. Viscosity Stability at $5^{\circ} \mathrm{C}$.

One component epoxy adhesive product normally needs storage conditions in a refrigerator or a freezer due to its high reactivity to ensure no obvious property change during storage before use. Typical storage temperatures used are around $5^{\circ} \mathrm{C}$ for refrigerator condition, $-20^{\circ} \mathrm{C}$ or $40^{\circ} \mathrm{C}$ for frozen storage. Viscosity of the novel epoxy adhesive stored at these three typical temperatures was measured periodically. Figure 4 shows the result at $5^{\circ} \mathrm{C}$ storage. As expected, viscosity increase rate became slower than that stored at room temperature, $25^{\circ} \mathrm{C}$ but its viscosity was still doubled within only a few days. Refrigerator storage is not suitable for this epoxy adhesive product due to its relatively short shelf life. Viscosity stability result at $-20^{\circ} \mathrm{C}$ frozen storage in Figure 5 Shows that the shelf life of this adhesive extended to a few months at $-20^{\circ} \mathrm{C}$ storage, indicating that short time storage is acceptable for this novel epoxy adhesive product. Figure 6 shows viscosity stability results for $-40^{\circ} \mathrm{C}$ frozen storage. As can be seen, there is completely no viscosity change for up to nearly three year storage at $-40^{\circ} \mathrm{C}$. The result showed that this novel one component epoxy adhesive product is extremely stable and its shelf life could be several years long at suitable frozen storage condition. The above measurements confirmed that this 
novel one component pure liquid thermal curable epoxy adhesive product possesses very good low temperature curability with useful level workability and long enough shelf life at suitable frozen storage condition.

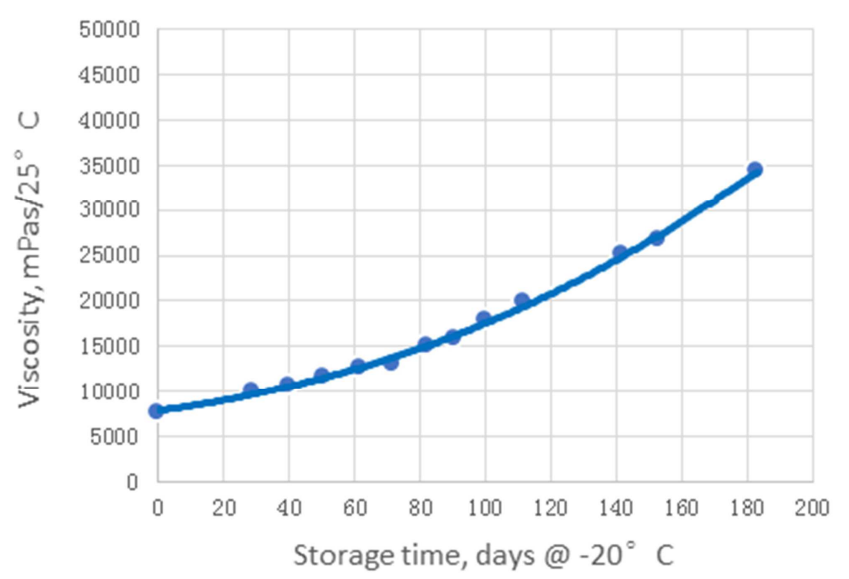

Figure 5. Viscosity Stability at $-20^{\circ} \mathrm{C}$.

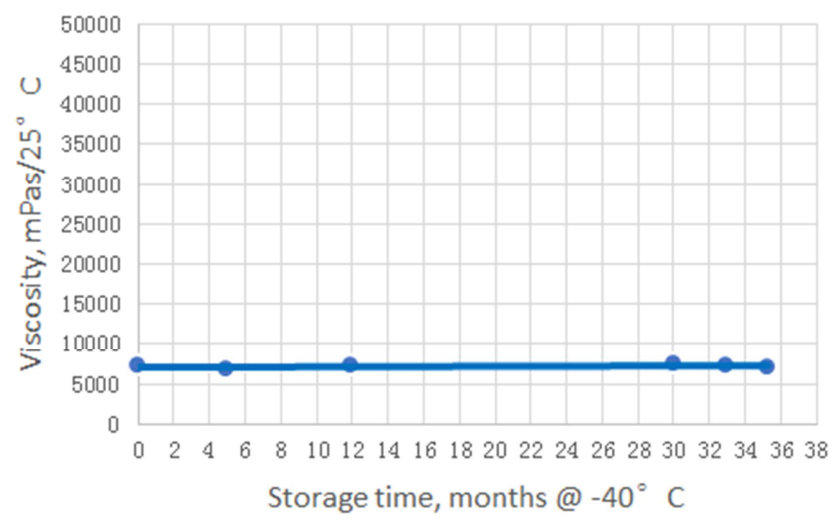

Figure 6. Viscosity Stability at $-40^{\circ} \mathrm{C}$.

\section{Discussion}

\subsection{Correlation Between Curability and Stability}

\subsubsection{Reaction Rate Determination}

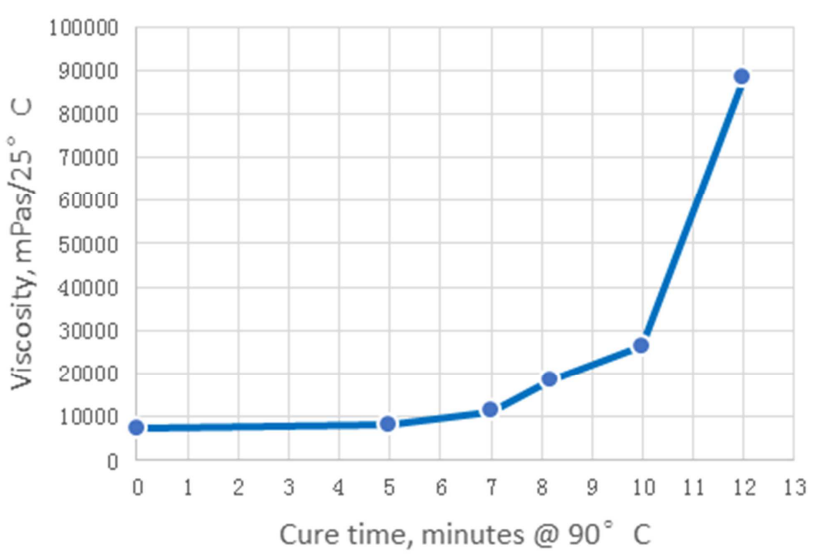

Figure 7. Viscosity Change at $90^{\circ} \mathrm{C}$ curing.

Viscosity increase of one component epoxy product is thought to be mainly resulted from curing reaction of epoxy resin. Figure 7 shows the viscosity increase curve at $90^{\circ} \mathrm{C}$ curing condition. Cure time when its viscosity increased to two times was measured at 7.5 minutes from the measured viscosity increasing curve. By analyzing DSC isothermal result at $90^{\circ} \mathrm{C}$ cure, cure degree for 7.5 minutes was measured at $3.51 \%$. In another word, cure degree of the novel epoxy adhesive is $3.51 \%$ when its viscosity increases to two times.

\subsubsection{Kinetic Plot}

By analyzing DSC isothermal result at other temperatures [27-30], cure time at $3.51 \%$ cure degree were calculated. The cure rate, abbreviated as $r$, was calculated at each cure temperature based on below formula where $\mathrm{t}$ is abbreviated from cure time: $\mathrm{r}=0.0351 / \mathrm{t}$. Analysis results on DSC isothermal chart from $80^{\circ} \mathrm{C}$ to $150^{\circ} \mathrm{C}$ cure are listed in Table 2. 1/Temperature and -Ln $\mathrm{r}$ are also calculated accordingly in order to confirm Arrhenius kinetics regression. The kinetics plot is shown in Figure 8. As can be seen, cure kinetics of this novel epoxy adhesive follow well with Arrhenius reaction model.

Table 1. DSC Cure Time at 3.51\% Cure Degree.

\begin{tabular}{llll}
\hline Temp. $\left({ }^{\circ} \mathbf{C}\right)$ & Temp.-1 (K-1) & $\begin{array}{l}\text { Time @ 3.51\% } \\
\text { conversion }(\mathbf{m i n})\end{array}$ & -Ln r, (sec-1) \\
\hline 80 & 0.002831 & 23.844 & 10.24 \\
90 & 0.002753 & 7.500 & 9.459 \\
100 & 0.00268 & 4.299 & 8.902 \\
110 & 0.00261 & 2.379 & 8.311 \\
120 & 0.002543 & 1.479 & 7.835 \\
130 & 0.00248 & 1.067 & 7.509 \\
140 & 0.00242 & 0.682 & 7.061 \\
150 & 0.002363 & 0.633 & 6.593 \\
\hline
\end{tabular}

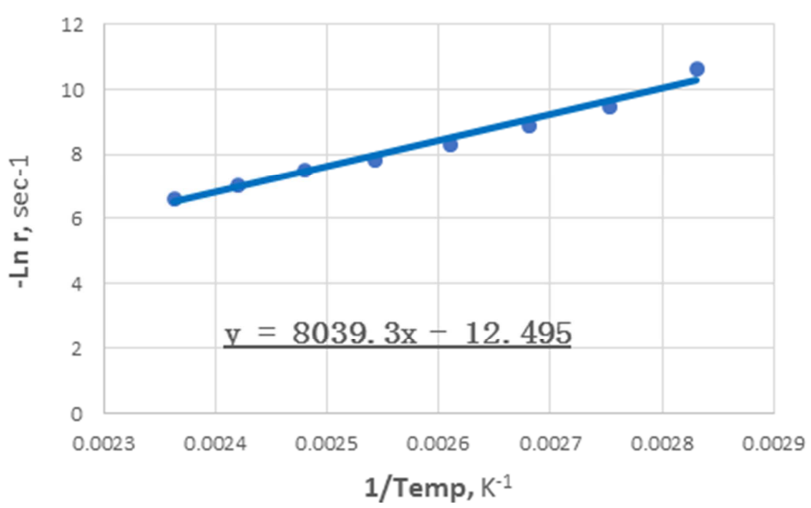

Figure 8. Arrhenius Kinetic Plot.

\subsubsection{Correlation Between Reactivity and Stability}

From Figure 8, kinetics equation is obtained as below where $t$ is the time when cure degree reaches to $3.51 \%$ which means viscosity increased to two times of intial one as described above. At lower storage temperatures, this t could be called as pot life at room temperature or shelf life at regregerator or freezer storage. From this kinetics equation, pot life and shelf life can be thus calculated simply. The calculated results with comparing to actual measred pot life and shelf life data are listed in Table 2. As shown clearly, 
calculated data correlate very well with actual measured pot life and shelf life results. This study verifies that DSC cure behavior results can be used also to predict stable behavior of one component epoxy adhesive.

-Ln r $=8039.3 /$ Temp-12.495

$$
\mathrm{t}=0.0351 \times \operatorname{EXP}[-(8039.3 / \text { Temp }-12.495)]
$$

Table 2. Shelf Life Comparison.

\begin{tabular}{lll}
\hline \multirow{2}{*}{ Storage condition } & \multicolumn{2}{l}{ Shelf life, days } \\
\cline { 2 - 3 } & Calculated & Measured \\
\hline @ $25^{\circ} \mathrm{C}$ & 18.6 hours & 19.2 hours, \\
@ $5^{\circ} \mathrm{C}$ & 5.4 & 5.6 \\
@ $-20^{\circ} \mathrm{C}$ & 93 & 82 \\
@ $-40^{\circ} \mathrm{C}$ & 1426 & $>1073$ \\
\hline
\end{tabular}

\subsection{Root Cause Analysis on $-40^{\circ} \mathrm{C}$ Stability}

From Figure 6, it was found that viscosity of the novel epoxy adhesive was extremely stable at $-40^{\circ} \mathrm{C}$ storage. There was completely no viscosity change for up to nearly threeyear storage. The stability behavior at $-40^{\circ} \mathrm{C}$ storage is much different from those when stored at $-20^{\circ} \mathrm{C}$ or above where its viscosity is observed to increase from the beginning. DSC was used also to measure phase change of the novel epoxy adhesive. As shown in Figure 9, there was a phase change observed at $-23.1{ }^{\circ} \mathrm{C}$. This temperature is believed to be crystallization temperature. The novel pure liquid epoxy adhesive would be changed to solid state below $-23.1^{\circ} \mathrm{C}$. Molecular movement of both epoxy resins and curing agent would be almost stopped at crystallized state and this is considered as the reason for outstanding long shelf life at $-40^{\circ}$ C storage. This finding could, on the other hand, help to design new epoxy products with longer shelf life by optimizing its crystallization temperature with adjustment on component ratio. This finding could be also utilized to determine best storage temperature by measuring its crystallization temperature with DSC method.

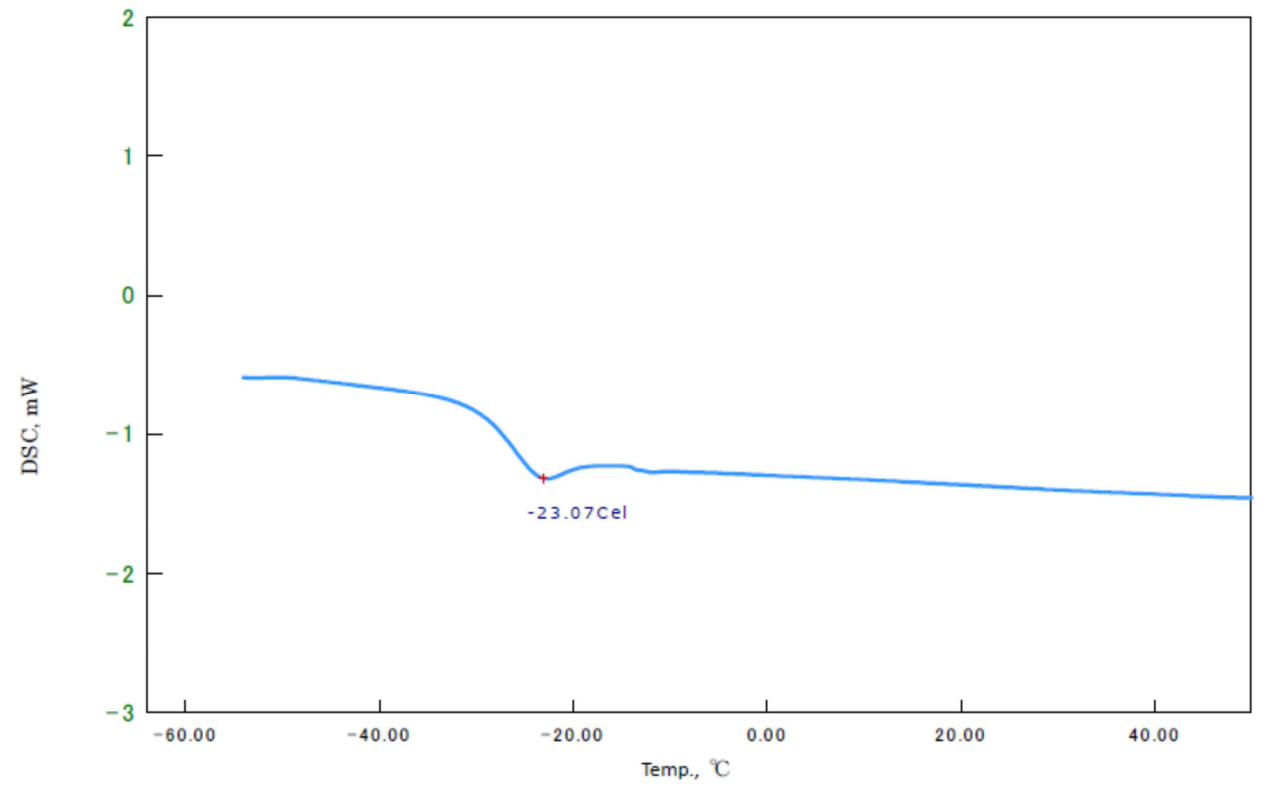

Figure 9. DSC Crystallization Temperature Result, scanning rate@ $5{ }^{\circ} \mathrm{C} / \mathrm{min}$.

\section{Conclusion}

Curability, workability and stability of a newly developed novel pure liquid one component thermal curable epoxy adhesive were investigated by viscosity and DSC measurement. The results confirmed that this novel adhesive possesses fast curability at relatively low temperature with useful level pot life and years long shelf life at suitable frozen storage. Regression study on cure Kinetics and stability shows very good correlation between calculated and real test result. This result verified that DSC isothermal measurement can be used to predict stability of one component epoxy adhesive product. In addition, it was found in this study that crystallization temperature measurement could be utilized for better stable epoxy adhesive development and best storage temperature determination.

\section{References}

[1] T. M. Groulding (2003), In Handbook of Adhesive Technology, 2nd Ed.; A. Pizzi, K. L. Mittal, Eds.; Marcel Dekker, 809-824.

[2] E. Sancaktar, L. Bai (2001), Polymers, 3, 27-466.

[3] C. Severijin, S. T. Freitas, J. A. Poulis (2017), Int. J. Adhes. Adhes., 75, 155-164.

[4] A. Zotti, S. Zuppolini, M. Zarrelli, A. Borriello (2016), In Adhesives-Applications and Properties, InTech, 237-269.

[5] T. Vidil, F. Tournilhac, S. Musso, A. Robisson, L. Leibler (2016), Prog. Polym. Sci., 62, 126-179.

[6] X. Liu, C. Zhao, A. Sudo, T. Endo (2013), J. Polym. Sci. Part A: Polym. Chem. 2013, 51, 3470-3476. 
[7] G. Rabilloud (1997), In High Performance Polymers, Editions Technip, 143.

[8] C. F. Chen (2008), Japan Patent 4204814.

[9] C. F. Chen, S. Iwasaki, M. Kanari, B. Li, C. Wang, D. Q. Lu (2017), IOP Conf. Ser.: Mater. Sci. Eng., 213, 012032.

[10] N. Poisson, A. Maazouz, H. Sautereau, M. Taha, X. Gambert (1998), J. Appl. Polym. Sci., 69, 2487-2497.

[11] K. Shiraishi (2001), Polym. Dig., 53 (6), 65-68.

[12] D. Lei, W. Ma, L. Wang, D. Zhang (2015), J. Appl. Polym. Sci., 42563.

[13] T. Hasekawa, M. Kobayashi (2017), Japan Patent $2017-$ 82219A.

[14] K. Arimitsu, S. Fuse, K. Kudo, M. Furutani (2015), Mater. Lett., 161, 408-410.

[15] K. Kudo, S. Fuse, M. Furutani, K. Arimitsu (2016), J. Polym. Sci. Part A: Polym. Chem., 54, 2680-2688.

[16] G. S. Kal, G. A. Vedage, S. M. Boyce, D. N. Shah, A. H. Abdourazak (2014), US Patent 20140303342A.

[17] J. Wang, Y. Z. Xu, Y. F. Fu, X. D. Liu (2016), Scientific Reports, 6, 38584.

[18] C. F. Chen, B. Li, C. Wang, S. Iwasaki, M. Kanari, D. Q. Lu (2018), Baekeland 2018, The 6th International Symposium on Network Polymers, Shanghai.
[19] W. Chen, P. Li, Y. Yu, X. Yang (2008), J. Appl. Polym. Sci., 107, 1493-1499.

[20] A. D. Rogers, P. Lee-Sullivan (2003), Polym. Eng. Sci., 43 (1), 14-24.

[21] M. Hayaty, M. H. Beheshy, M. Esfandeh (2011), Polym. Adv. Technol., 22, 1001^1006.

[22] S. Vyazovkin, N. Sbirrazzuoli (1996), Macromolecules, 29, 1867-1873.

[23] J. Macan, I. Brnardic, M. Ivankovic, H. J. Mencer (2005), J. Therm. Ana. Calor., 81, 369-373.

[24] S. Park, M. Seo, J. Lee (2000), J. Polym. Sci. Part A: Polym. Chem., 38, 2945-2956.

[25] L. Feng, Y. Wang, Y. Wang, H. Liu, J. Zhao (2013), J. Appl. Polym. Sci., 1895-1990.

[26] D. E. Lee, H. W. Kim, B. S. Kong, H. O. Choi (2017), J. Appl. Polym. Sci., 45252.

[27] A. A. A. Razak, N. J. Saleh (2016), Eng. \& Tech. Journal, 34 (9), 1731.

[28] R. Nurhayati, E. Rahayu NH, A. Susanto, Y. Khasanah (2017), IOP Conf. Ser.: Mater. Sci. Eng., 193, 012025.

[29] I. Blanco (2018), Materials, 11, 1383.

[30] A. Bernath, L. Karger, F. Henning (2016), Polymers, 8, 390. 